$\xi=-1$

\title{
Parameters Affecting Coating Uniformity of Alkali -Activated Material Coated Fertilizer
}

\author{
Luqman Hakim H. ${ }^{1 *}$, Ku Zilati KZ. ${ }^{1}$, Muhammad Harris N. ${ }^{1}$ \\ ${ }^{I}$ Department of Chemical Engineering, Universiti Teknologi PETRONAS, Malaysia \\ *Corresponding author E-mail luqman.hakim_g03273@utp.edu.my
}

\begin{abstract}
The establishment of Controlled Release Urea (CRU) in agriculture industry has given a great significant outcome towards the development of economy while preserving the environment. As it is developed through a coating process, it does not only help to increase fertilizer's efficiency, but also minimize the loss of nutrients into the soil and environmental pollution. There are many types of coating materials that have been extensively studied as well as applied in everyday life from pharmaceutical industry to engineering industry such as in pharmaceutical tablet, road construction and corrosion control of steel structures like offshore platforms. In this research, the alkaliactivated material composite has been developed as a new coating material and is introduced as the main coating material for the CRU. In term of environmental friendliness, alkali-activated material (AAM) is considered better than sulphur and polymer. However, the combination of fly ash and sodium hydroxide $(\mathrm{NaOH})$ solution producing the AAM paste needs further research since it can be categorized as a novel coating material for CRU. It is also to ensure the suitability of it to be used as a coating material on urea fertilizer. A significant coating thickness along with good hardness strength can produce promising coated urea granules characteristics. Two parameters have been studied for this research to identify its effect towards coating thickness and hardness strength of coated urea granules which are inlet air pressure and spraying rate. These two parameters are identified to be crucial in enhancing the characteristics of coated urea granules.
\end{abstract}

Keywords: controlled release urea; alkali-activated material; inlet air pressure; spraying rate; coating thickness.

\section{Introduction}

The necessity of agriculture is rarely questioned as it is important to feed the world's population [1]. It has always been a vital contributor towards sustaining human life for a long time. Farming has seen new turns with its inextricable and an integral part with human daily activities. Change of lifestyle, technology, and especially industrial revolution have played a crucial role in changing the shape of modern agriculture values. The introduction of agricultural fertilizers has marked the new cultivation revolution with its variety of types and its function to promote and enhance the productivity of commercial crops such as paddy and palm oil. One of the popular fertilizers that is used widely today is urea [2]. As a nitrogen fertilizer, beside its high demand usage in agriculture due to its high content of nitrogen (45\%), its property of high solubility in water makes it suitable for soil application. However, it causes the nutrients to be absorbed into the soil rapidly and excessively during early plant growth stage. This is due to its vulnerability from volatilization and leaching when applied to crops [3]. Moreover, the denitrification process also happens as the fertilizer nutrient is lost into the atmosphere in the form of nitrogen gas. A technique known as controlled release urea (CRU) has been introduced to counter this problem by using the thin-film technology [4]. This technique works by controlling the amount of nutrients released from urea granule. It is proved to boost crop yield while reducing the environmental pollution caused by hazardous emissions such as ammonia, nitrous oxide and etc. from current fertilizer practices [5]. Researchers had been investigating and developing this innovative technology to optimize the absorption of nutrient for crop and at the same time minimizing the impact towards environment [6-9]. CRU is urea granule coated with a mixture of various materials which will reduce the releasing period of nutrients and control the amount of nutrients released to plant subsequently. There are many coating materials that can be used to control the release of urea [7,9]. In this study, the fly ash blends has been proposed to be used as the coating material for this research due to its green property and environmental friendly nature [10]. Several aspects need to be considered in conducting the coating process such as the compatibility of the coating material with the substrate and the environmental aspect.

\subsection{Controlled Release Urea (CRU)}

About half of the world crop yields have been attributed to commercial fertilizers [11]. In the early days, CRUs are considered too expensive to be used in a small area of production. But the recent development of lower-cost polymer-coated urea products has led to consideration of their use in a wide range especially in agriculture sectors [12]. CRU is a purposely designed manure which releases fertilizing nutrients in a controlled, delayed manner in line with the sequential needs of plants for nutrients, thus providing enhanced nutrient use efficiency along with enhancing yields [5].

An ideal CRU is the one that coated with a natural or semi-natural, environmentally friendly macro-molecule that decelerates fertilizer release to such a slow rate that a single application to the soil can meet nutrient requirements for model crop growth [13]. Fur- 
thermore, the use of CRU from the plant treated with it, is substantial and performs significantly compared to urea granule. Roughly $40 \%$ to $70 \%$ of nitrogen in normal fertilizers vaporized to the environment which can give a huge impact on economy, causes loss of resource as well as contribute environmental pollution [14-16]. The diffusion mechanism can be explained using Figure 1. It shows the diffusion mechanism of controlled release urea. Picture (a) shows urea core with polymer coating while picture (b) shows water penetrates the coating and core granule. Next is the picture (c) showing the urea dissolution and development of osmotic pressure and lastly, picture (d) displayed the controlled release nutrient diffuse out through swollen coating membrane.

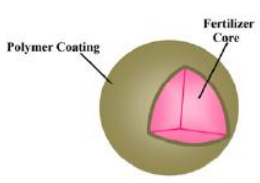

a

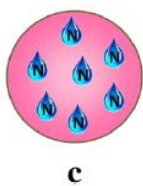

c

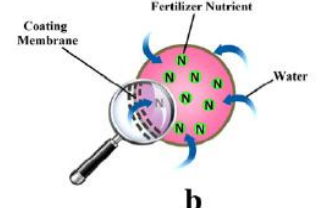

b

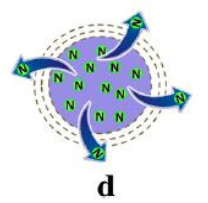

Fig. 1: Diffusion mechanism of control released [3]

\subsection{Thin-Film Coating Technology}

One crucial aspect of the process of producing the controlled release urea is a technology known as a thin-film coating. It is where a thin layer ranging from nanometers to several micro-metres in thickness is formed by the coating material [17]. Several techniques are known in performing the thin-film coating. Different techniques have been studied by researches for the coating process such as fluidized bed, spouted bed and rotating drum, with various coating materials like resin, sulphur, and polymers [18, 19]. During the coating process, the sprayed liquid will mix with the solid bed material [20]. When the coating droplets come in contact with the particles' surface, the droplets of liquid will spread, and the solid particle is coated partially. The repeated movement of particles through the spray zone will continuously coat all over the solid material. This result in smooth and uniform coating. Diagram in Figure 2 presented each step mechanism of coating process, starting from spraying, wetting, and recrystallization to finally becomes coated particle.

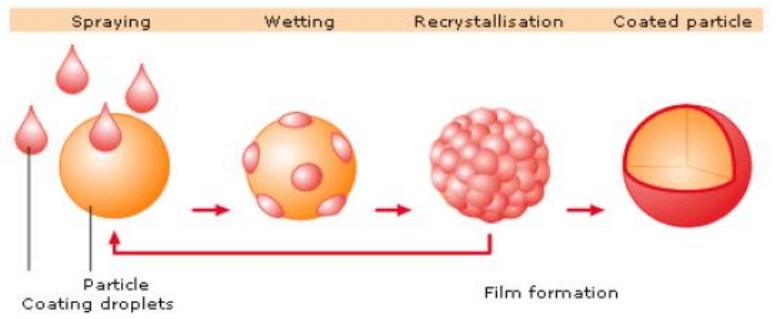

Fig. 2: Coating Mechanism [21]

\subsection{Fly Ash Used for Coating Material}

Fly ash has been used and applied commercially in construction, fire protection, thermal insulation, etc. From the environmental point of view, carbon dioxide emission is less produced [22] and the consumption of energy is low [23] when fly ash is used. As a result, the effect of global warming can be reduced and therefore help to save the environment.

\subsection{Coating Parameters}

The coating is applied for a number of reasons including masking unpleasant taste or odour of the ingredients, enhancing the appearance of the product, modifying its dissolution rate and to add active drug molecules to the tablet [24]. Meeting strict quality control standards for every batch of coated tablets is very tricky. Usually, there is an unexpected batch failure that is hard to explain especially due to a lack of process understanding. Moreover, there is a complex interplay between multiple parameters and devicespecific factors within the process itself. The relative effect of droplet size, impact and frequency, liquid spreading, drying and the ensuing solid-state transformations determine the morphology and quality of the coating [25]. Operational parameters can be divided into two groups during the process of pan-coating. They are pan-and-tablet-related namely; pan diameter and depth, pan speed, pan load, baffle setup and pan perforation, and sprayrelated namely; spray rate, inlet air flow rate, inlet air pressure, atomizing air and coating time [26, 27].

Thus, it is crucial to identify these parameters and understand their effects on the product quality. The coating pan's speed of rotation, loading level of the pan, type of spray pattern and the efficiency of nozzles are some of the of parameters that are being concerned in this study and is set as constant parameters. This study is limited only to the study using a coating pan for the inlet air pressure and spraying rate towards coating thickness and hardness strength. Air pressure is needed for the spray gun to be able to atomize the slurry out from the nozzle with compressed air. Air is being supplied through inlet air source via a tube and is monitored using meter pressure.

\section{Methodology}

\subsection{Coating Solution Preparation}

The coating solution is prepared from the combination of fly ashbased powder and sodium hydroxide $(\mathrm{NaOH})$ solution. The preparation method and blending ratio for the coating solution is referred from Abdul Rahim et al. [33] with a ratio of 3:1. The coating solution is prepared by mixed the $600 \mathrm{~g}$ of fly ash-based powder along with 200 gram of $\mathrm{NaOH}$ solution of $10 \mathrm{M}$. This is followed by stirring the solution in a hot plate using magnetic stirrer for 30 minutes.

\subsection{Experimental Setup}

A pan coater is used to film-coat the urea granules with AAM paste. The conditions and settings inside the pan coater are measured and monitored throughout the process. In the control screen, the operation interface is used for controlling the process parameters. The amount of urea granules used as the starting material for this work is 150 gram. Firstly, the urea granules are preheated for 20 minutes. After that, comes the spraying process whereby it is executed for 50 minutes. When the spraying process is done, the drying process is performed for 10 minutes.

\subsection{Evaluation of Coated Urea Granules}

\subsubsection{Coating Thickness}

According to Hassan et al. [34], from each experiment run, thirty coated urea granules are selected randomly. The coated urea granules are cut diametrically into halves using a sharp knife. Coated urea granules cross-sections are examined under an optical microscope under 5x magnifications, with the cut surface facing up. Images are captured with a digital microscope camera. For each sample, two readings are taken on the cross-section of the coated urea granules. 


\subsubsection{Hardness Strength}

In every experiment, several selected coated urea granules are tested for their hardness strength using digital hardness analyzer [35]. The coated urea granules are being placed on the sample support. As the driven force jaw moves towards the sample, it started to increase the force. The force continues to increase as the jaw touches the sample up to the point until the coated urea granule breaks. This resulted to the force values being shown at the display of the tablet hardness tester. The total of 30 randomly selected coated urea granules are being tested after every experiment. Later, the average hardness in Newton $(\mathrm{N})$ is calculated per experiment.

\subsection{Design of Experiment (DoE)}

The full factorial design is used as the DoE in this research since it is regularly being used in industry. It is an orthogonal array design type that allows experimenters to study main effects and desired interaction effect in a minimum number of trials or experimental runs. According to Box et al., [36], the designs are normally represented in the form of $2^{(\mathrm{k}-\mathrm{p})}$, where $\mathrm{k}$ is the number of factors and $1 / 2^{\mathrm{P}}$ represents the fraction of the full factorial. Accordingly, 2 factors of experimental procedure are tested whereby each run at 3 levels, therefore 9 different combinations of the levels are designed, as shown below (Table 1).

Table 1: The experimental layout of $3^{2}$

\begin{tabular}{c|c|c|}
\hline Trial & Inlet air pressure, P (bar) & Spraying rate, R (rpm) \\
\hline 1 & -1 & -1 \\
2 & -1 & 0 \\
3 & -1 & +1 \\
4 & 0 & -1 \\
5 & 0 & 0 \\
6 & 0 & +1 \\
7 & +1 & -1 \\
8 & +1 & 0 \\
9 & +1 & +1 \\
\hline \multicolumn{4}{c}{} \\
Notation: & & \\
\hline Sign & $\mathrm{P}$ (bar) & $\mathrm{R}(\mathrm{rpm})$ \\
\hline-1 & 0.3 & 10 \\
0 & 0.5 & 30 \\
+1 & 0.7 & 50 \\
\hline
\end{tabular}

\section{Results and Discussion}

Testing for coating thickness and hardness strength has been done to determine the physical properties of the AAM coated sample. This is to ensure that the objective of this project which is enhancing the characteristics of coated urea granules complies with the parameters that have been set up.

\subsection{Coating Thickness}

The purpose of coating thickness analysis is to figure out the length of AAM coating thickness on urea granule surface. The reason coating thickness is being measured is find out the average coating thickness per tablet to ensure coating uniformity achievable. Coating uniformity is described as having coating material to be equal in every angle and side of a granule. Figure 3 shows the example images of each trial.

\begin{tabular}{ccc}
\hline $\begin{array}{c}\text { Trial } \\
\text { No. }\end{array}$ & $\begin{array}{c}\text { The image is taken from } \\
\text { the top left side on a cross- } \\
\text { section of the coated urea } \\
\text { granule }\end{array}$ & $\begin{array}{c}\text { The image is taken from } \\
\text { the bottom right side on a } \\
\text { cross-section of the coated } \\
\text { urea granule }\end{array}$ \\
\hline 1 & & \\
\hline
\end{tabular}

2

5
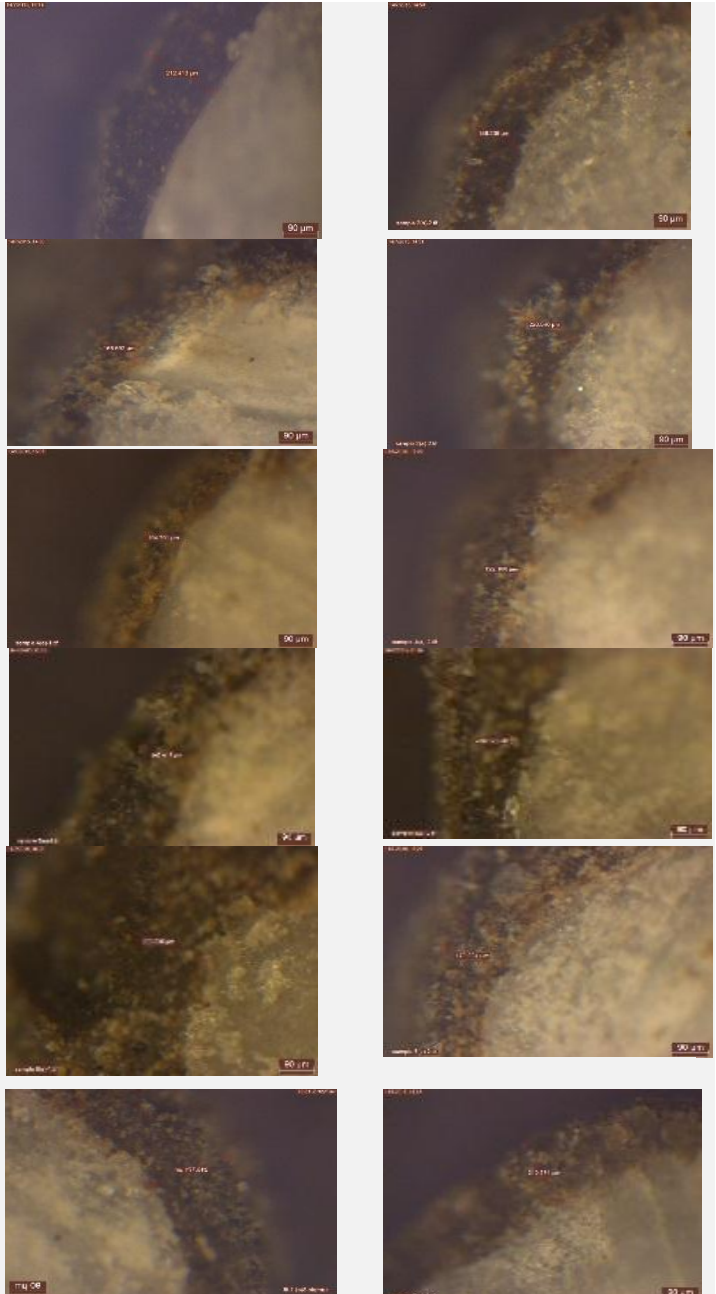

8
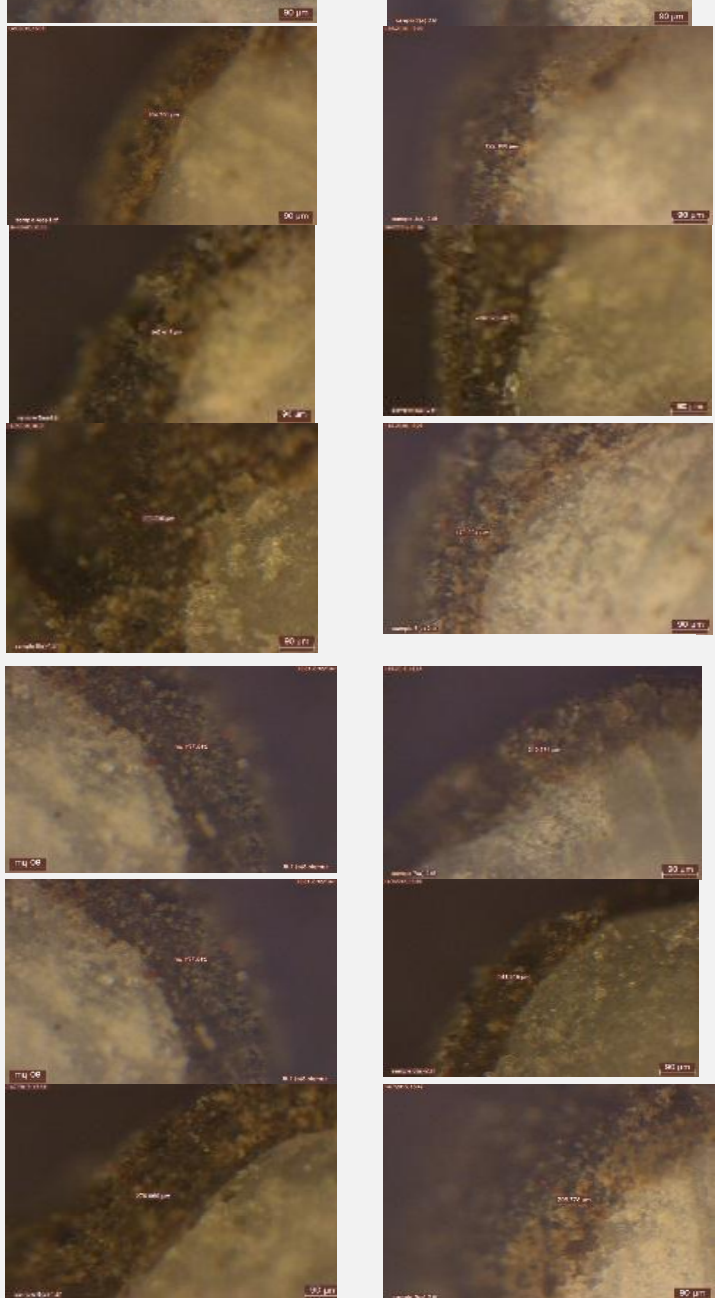

9

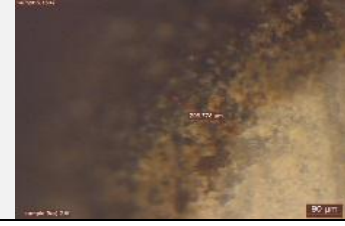

Fig. 3: Example of images of cross section of the coated urea granule from each trial

\subsubsection{Inlet Air Pressure}

Based on Figure 4 below, the graph of thickness versus inlet air pressure shows up trending line of which the coating thickness is kept increasing when inlet air pressure was from 0.3 bar to 0.7 bar. The trending indicates that inlet air pressure plays a major role in determining the thickness of AAM coating of a sample. The certain explanation based on the experiment of which thickness at inlet air pressure 0.7 bar $(203.649 \mu \mathrm{m})$ is higher than $0.3 \mathrm{bar}$ $(178.78 \mu \mathrm{m})$ and $0.5 \mathrm{bar}(178.782 \mu \mathrm{m})$ due to the fact that inlet air pressure controls the coating solution flow and automatically manages the droplet size from the spray nozzle. It is in line with Pandey et al. [37] that mentioned higher inlet air pressure produces small droplet size and produced better coating layer. In this study, it produces good coating thickness. 


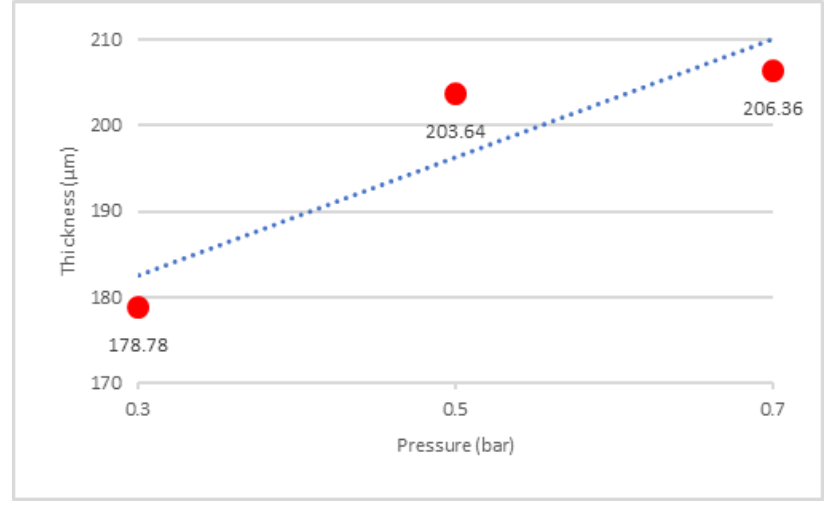

Fig. 4: Thickness Vs Pressure Graph

\subsubsection{Spraying rate}

According to Figure 5, the higher the spraying rate, the higher the coating thickness. This shows that spraying rate is one of the important factors in ensuring the thickness of the AAM coated sample to be managed. The simple explanation of this case is that as spraying rate increases, more AAM slurry is being applied on top of the granule bed by layer after layer [38]. There is also a downside to this method that is as the spraying rate goes higher, fill load is getting thicker on the top surface of the granule bed [39], making it harder to dry as preparation for the next coating layer. As the process is running, the amount of urea granule sticking to each other is increasing. This phenomenon is what we call agglomeration [40]. Thus, to find the perfect coating thickness of urea granule, the selected parameters that are being used during the experiment must be limited to $50 \mathrm{rpm}$ spraying rate. This maximum amount of coating solution spraying rate was according to preliminary experiment. A large quantity of agglomeration of coated urea sample is a sign that the level of parameters used is not suitable. Coating uniformity will be unachievable if this process is to happen.

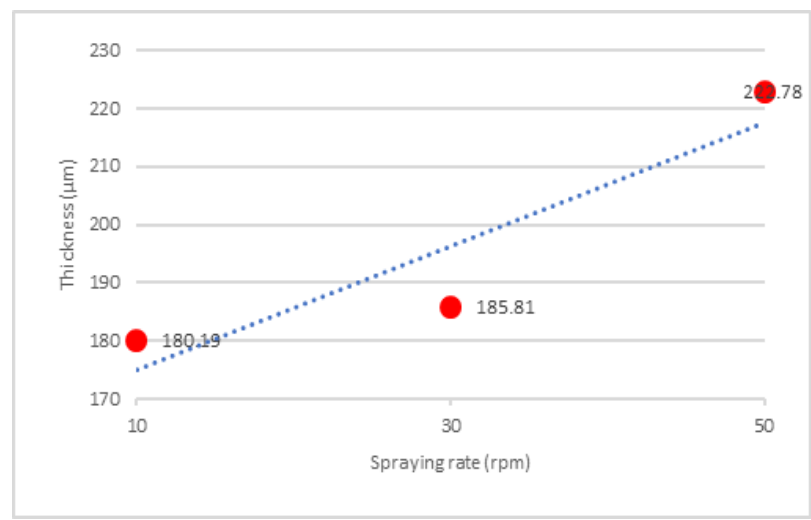

Fig. 5: Thickness Vs Pressure Graph

\subsection{Hardness Strength}

Hardness strength is conducted to find out how hard the coating can withstand when being pressurized by a certain amount of force. This is an important physical property as it affects the reliability of the coating uniformity of a coated urea granule. The hardness of a coating material relates to the amount of slurry that is applied to the urea sample during the coating process. Therefore, by knowing the hardness of a coated sample, valuable information regarding other factors such as coating time, the rate of rotation and shaking, etc., can be predicted mostly by observation during experimental work.

\subsubsection{Inlet Air Pressure}

Based on Figure 6, the inlet air pressure is varied at 0.3 bar, 0.5 bar and 0.7 bar. The hardness strength of coated urea granule at pressure 0.7 bar was decreased from $41.93 \mathrm{~N}$ to $38.26 \mathrm{~N}$ can be explained largely due to the influence of inlet air pressure itself. Too much inlet air pressure cause the spraying pattern of the slurry to change. As the slurry is being sprayed out through the nozzle, the pattern can come out in the form of wide, narrow, horizontal and even vertical [41]. Even though horizontal and vertical pattern can be made set at the nozzle, the force of pressure can somehow make the slurry come out in a disoriented pattern.

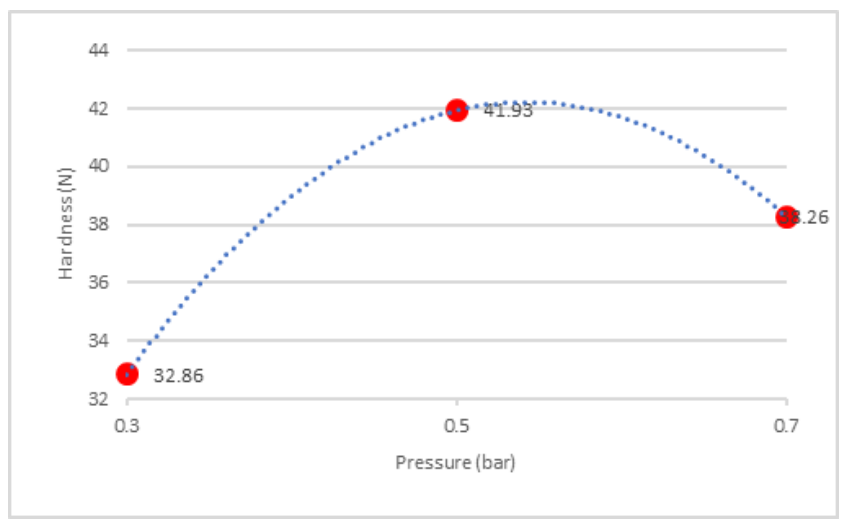

Fig. 6: Hardness Vs Pressure Graph

\subsubsection{Spraying Rate}

Based on Figure 7, the hardness strength increased as spraying rate increased from $30 \mathrm{rpm}$ to $50 \mathrm{rpm}$ which is from $39.93 \mathrm{~N}$ to 41 $\mathrm{N}$. The hardness is then decreased tremendously when spraying rate at $50 \mathrm{rpm}$ is applied to hardness strength of $32.13 \mathrm{~N}$. The result contradict several studies which mentioned hardness strength commonly will be increased as spraying rate was increased [38, 42]. However, it should be noted that the parameter level of spraying rate in this study is higher from them. In this study, spraying rate at $50 \mathrm{rpm}$ will give more pressure onto the urea granule surface during spraying process due to high spraying rate. Thus, it will lead the urea granule towards the wall and collision between urea granules. Ultimately, it will lead to attrition and breakage.

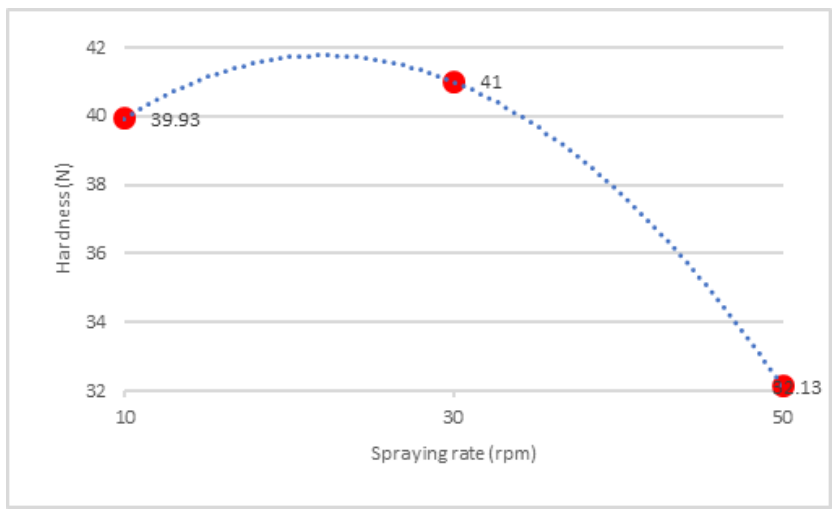

Fig. 7: Hardness Vs Spraying Rate Graph

\section{Conclusion}

The coating of urea is needed to avoid unnecessary nutrients loss through leaching, volatilization, and denitrification. The alkaliactivated material is the future substance that should be used as coating material. A greatly controlled release of urea provides necessary nutrients for the plant to grow at the right time with the right nutrients amount. From this study, it shows that the two selected parameters are highly important in ensuring the coating 
thickness and hardness strength of the coated urea granules. The level of inlet air pressure and spraying rate for coating thickness were at a high level and for hardness strength was at a moderate level.

\section{Acknowledgement}

The author would like to acknowledge YTL Cement Berhad, Westport, Selangor for supplying fly ash and Ministry of Education Malaysia for a scholarship under MyBrain15 Program.

\section{References}

[1] Atapattu, S.S. and D.C. Kodituwakku, Agriculture in South Asia and its implications on downstream health and sustainability: a review. Agricultural Water Management, 2009. 96(3): p. 361-373.

[2] Heffer, P. and M. Prud'homme, Global Nitrogen Fertilizer Demand and Supply: Trend, Current Level and Outlook. 2016.

[3] Azeem, B., et al., Review on materials \& methods to produce controlled release coated urea fertilizer. Journal of Controlled Release, 2014. 181(Supplement C): p. 11-21.

[4] Trenkel, M.E., Slow-and controlled-release and stabilized fertilizers: An option for enhancing nutrient use efficiency in agriculture. 2010: IFA, International fertilizer industry association.

[5] Shaviv, A., Controlled Release Fertilizers. IFA International Workshop on Enhanced-Efficiency Fertilizers, Frankfurt. International Fertilizer Industry Association, Paris, France, 2005.

[6] Salman, O.A., Polyethylene-Coated Urea. 1. Improved Storage and Handling Properties. Industrial and Engineering Chemistry Research, 1989. 28(5): p. 630-632.

[7] Tomaszewska, M. and A. Jarosiewicz, Use of polysulfone in controlled-release NPK fertilizer formulations. Journal of Agricultural and Food Chemistry, 2002. 50(16): p. 4634-4639.

[8] Abraham, J. and V.N.R. Pillai, Membrane-encapsulated controlledrelease urea fertilizers based on acrylamide copolymers. Journal of Applied Polymer Science, 1996. 60(13): p. 2347-2351.

[9] Yang, Y.C., et al., Improving the quality of polymer-coated urea with recycled plastic, proper additives, and large tablets. Journal of Agricultural and Food Chemistry, 2012. 60(45): p. 11229-11237.

[10] Teixeira-Pinto, A., et al., Geopolymer-Jute Composite: A Novel Environmentally Friendly Composite with Fire Resistant Properties. Developments in Porous, Biological and Geopolymer Ceramics: Ceramic Engineering and Science Proceedings, Volume 28, Issue 9, 2009: p. 337-346.

[11] Stewart, W., et al., The contribution of commercial fertilizer nutrients to food production. Agronomy Journal, 2005. 97(1): p. 1-6.

[12] Nelson, K., et al., Agricultural management of enhanced-efficiency fertilizers in the north-central United States. Crop Management, 2008. 7(1): p. 0-0

[13] Blouin, G.M. and D.W. Rindt, Method of making sulfur-coated fertilizer pellet having a controlled dissolution rate. 1967, Google Patents.

[14] Dave, A., et al., A review on controlled release of nitrogen fertilizers through polymeric membrane devices. Polymer-Plastics Technology and Engineering, 1999. 38(4): p. 675-711.

[15] Zhan, F., et al., Preparation of superabsorbent polymer with slow-release phosphate fertilizer. Journal of Applied Polymer Science, 2004. 92(5): p. 3417-3421.

[16] Liu, M., et al., Preparation of superabsorbent slow release nitrogen fertilizer by inverse suspension polymerization. Polymer international, 2007. 56(6): p. 729-737.

[17] Chen, L., et al., Controlled release of urea encapsulated by starch-gpoly (L-lactide). Carbohydrate polymers, 2008. 72(2): p. 342-348.

[18] Anggoro, D.D., Producing slow release urea by coating with starch/acrylic acid in fluid bed spraying. 2011.

[19] Ku Shaari, K.Z., L.H. Hassan, and Z. Man. Optimization of Coating Thickness in a Tangential Fluidized Bed. in Applied Mechanics and Materials. 2014. Trans Tech Publ.

[20] Werner, S.R., et al., Air-suspension particle coating in the food industry: Part I-State of the art. Powder Technology, 2007. 171(1) p. 25-33.

[21] K. Eichler, Process selection. 1989, Glatt GmbH, Binzen.

[22] Duxson, P., et al., The role of inorganic polymer technology in the development of 'green concrete'. Cement and Concrete Research, 2007. 37(12): p. 1590-1597.
[23] $\mathrm{Xu}, \mathrm{H}$., et al., Low-reactive circulating fluidized bed combustion (CFBC) fly ashes as source material for geopolymer synthesis. Waste Management, 2010. 30(1): p. 57-62.

[24] Dubey, A., et al., Effect of speed, loading and spray pattern on coating variability in a pan coater. Chemical engineering science, 2011. 66(21): p. 5107-5115.

[25] Bolleddula, D., A. Berchielli, and A. Aliseda, Impact of a heterogeneous liquid droplet on a dry surface: Application to the pharmaceutical industry. Advances in colloid and interface science, 2010. 159(2): p. 144-159.

[26] García-Muñoz, S. and D.S. Gierer, Coating uniformity assessment for colored immediate release tablets using multivariate image analysis. International journal of pharmaceutics, 2010. 395(1): p. 104-113.

[27] Rostam, O., et al. Assessing the Significance of Rate and Time Pulse Spraying in Top Spray Granulation of Urea Fertilizer Using Taguchi Method. in Applied Mechanics and Materials. 2015. Trans Tech Publ.

[28] Just, S., et al., Optimization of the inter-tablet coating uniformity for an active coating process at lab and pilot scale. International journal of pharmaceutics, 2013. 457(1): p. 1-8.

[29] Rege, B.D., J. Gawel, and J.H. Kou, Identification of critical process variables for coating actives onto tablets via statistically designed experiments. International journal of pharmaceutics, 2002 237(1): p. 87-94.

[30] Tobiska, S. and P. Kleinebudde, Coating uniformity and coating efficiency in a Bohle Lab-Coaterusing oval tablets. European journal of pharmaceutics and biopharmaceutics, 2003. 56(1): p. 3-9.

[31] Kalbag, A., et al., Inter-tablet coating variability: residence times in a horizontal pan coater. Chemical Engineering Science, 2008. 63(11): p. 2881-2894.

[32] Kalbag, A. and C. Wassgren, Inter-tablet coating variability: Tablet residence time variability. Chemical Engineering Science, 2009. 64(11): p. 2705-2717.

[33] Abdul Rahim, R., et al., Comparison of Using $\mathrm{NaOH}$ and $\mathrm{KOH}$ Activated Fly Ash-Based Geopolymer on the Mechanical Properties. 2014.

[34] Hassan, L.H., K. KuShaari, and Z. Man, Urea Hardness Optimization in a Fluidized Bed Coating Equipment using Taguchi Design Method. Applied Mechanics \& Materials, 2014. 699.

[35] Subramonian, S., et al., Top Spray Fluidized Bed Granulated Paddy Urea Fertilizer. Applied Mechanics and Materials, 2014. 606: p. 137-140.

[36] Box, G.E., W.G. Hunter, and J.S. Hunter, Fractional factorial designs at two levels. Statistics for experimenters. An introduction to design, data analysis and model building. John Wiley \& Sons, New York, NY, 1978: p. 374-418.

[37] Pandey, P., et al., Scale-up of a pan-coating process. AAPS PharmSciTech, 2006. 7(4): p. E125-E132.

[38] Palamanit, A., et al., Effects of inlet air temperature and spray rate of coating solution on quality attributes of turmeric extract coated rice using top-spray fluidized bed coating technique. Journal of food engineering, 2013. 114(1): p. 132-138.

[39] Terrazas-Velarde, K., M. Peglow, and E. Tsotsas, Stochastic simulation of agglomerate formation in fluidized bed spray drying: a micro-scale approach. Chemical Engineering Science, 2009. 64(11): p. 2631-2643.

[40] Sahni, E. and B. Chaudhuri, Experiments and numerical modeling to estimate the coating variability in a pan coater. Internationa journal of pharmaceutics, 2011. 418(2): p. 286-296.

[41] Rege, B.D., J. Gawel, and J.H. Kou, Identification of critical process variables for coating actives onto tablets via statistically designed experiments. International journal of pharmaceutics, 2002. 237(1): p. 87-94.

[42] Ruotsalainen, M., Studies on aqueous film coating of tablets performed in a side-vented pan coater. 2003. 